\title{
Malignant Lymphoma with Initial Symptoms in the Mandibular Region
}

\author{
Yumi Mochizuki', Hiroyuki Harada1 ${ }^{*}$, Kei Sakamoto², Kou Kayamori'2, Shin Nakamura ${ }^{3}$, \\ Minoru Ikuta1, Yuji Kabasawa1, Eriko Marukawa1, Hiroaki Shimamoto1, \\ Fumihiko Tushima ${ }^{1}$, Ken Omura ${ }^{1}$ \\ ${ }^{1}$ Oral and Maxillofacial Surgery, Department of Oral Restitution, Division of Oral Health Sciences, Graduate \\ School, Tokyo Medical and Dental University, Tokyo, Japan \\ ${ }^{2}$ Molecular Pathology, Department of Oral Restitution, Division of Oral Health Sciences, Graduate School, \\ Tokyo Medical and Dental University, Tokyo, Japan \\ ${ }^{3}$ Oral Radiology, Department of Oral Restitution, Division of Oral Health Sciences, Graduate School, Tokyo \\ Medical and Dental University, Tokyo, Japan \\ Email: ${ }^{*}$ hiro-harada.osur@tmd.ac.jp
}

Received 31 May 2015; accepted 10 July 2015; published 13 July 2015

Copyright (C) 2015 by authors and Scientific Research Publishing Inc.

This work is licensed under the Creative Commons Attribution International License (CC BY).

http://creativecommons.org/licenses/by/4.0/

(c) (i)

Open Access

\section{Abstract}

Primary intraosseous lymphoma is rare and there are few case reports manifesting with a mass in the mandible. Thus, we retrospectively reviewed and analyzed the clinical characteristics, treatment, and outcome of extranodal non-Hodgkin's lymphoma (NHL) with initial mandibular symptoms in our department. At initial treatment of dental clinics, dentists had diagnosed as dental or gingival diseases and had performed dental treatment. Neurological disorder to involvement of the inferior alveolar nerve was present in $80.0 \%$ of our cases. On dental or panoramic radiography a specific radiolucent lesion in the mandible was not detected, except for dental lesions. On CT, NHL of the mandible region has no widening and no clear destruction but a slit-like the cortex bone destruction pattern with keeping in shape of the mandibular body $(62.5 \%$ of CT-examined cases), and extraosseous soft tissue mass are clearer on MRI (100.0\% of MRI-examined cases). Histopathologically, $\mathbf{8 0 . 0 \%}$ of our cases were diagnosed as diffuse large B cell lymphoma (DLBCL). One case as B-cell lymphoblastic lymphoma and one case as B-cell lymphoma unclassifiable with features intermediate between DLBCL and Burkitt lymphoma were Stage IV (Ann Arbor staging system) and had poor prognosis. The disease-specific survival rate was $77.8 \%$ at 5 years. If unexplained non-specific symptoms such as swelling of the jaw, pain, neurological disorder of the inferior alveolar nerve, tooth mobility are observed, oral surgeons and dentists should not perform dental treatments. CT and MRI show disease specific appearance to be able to give a definitive diasnosis as NHL. PET/CT is useful for scaninng of whole body. A deep bone biopsy is preferred for suspected malignant lymphoma.

${ }^{*}$ Corresponding author.

How to cite this paper: Mochizuki, Y., Harada, H., Sakamoto, K., Kayamori, K., Nakamura, S., Ikuta, M., Kabasawa, Y., Marukawa, E., Shimamoto, H., Tushima, F. and Omura, K. (2015) Malignant Lymphoma with Initial Symptoms in the Mandibular Region. Journal of Cancer Therapy, 6, 554-565. http://dx.doi.org/10.4236/jct.2015.67060 


\section{Keywords}

\section{Mandible, Diffuse Large B Cell Lymphoma, B-Cell Lymphoma Unclassifiable with Features Intermediate between DLBCL and Burkitt Lymphoma, B-Cell Lymphoblastic Lymphoma, The Inferior Alveolar Nerve}

\section{Introduction}

Malignant lymphoma is a malignancy of the lymphatic system with proliferation of malignant lymphoid cells or their precursors, [1] and is generally classified as either Hodgkin's or non-Hodgkin's lymphoma (NHL) [2]. Oral NHL account for $3.5 \%$ of intraoral malignancies and $2.5 \%$ of all NHL [3]. Primary intraosseous lymphoma is rare [4]. Huvos reported that 8 (5.8\%) of 158 cases of NHL in the bone had involved the mandible [5]. There have been several reportes of malignant lymphoma of the mandible and many of them were aggressive with a poor prognosis [3] [6]. Malignant lymphoma has been reviewed and newly categorized in the latest edition of the World Health Organization (WHO) Classification of Tumours of Haematopoietic and Lymphoid Tissues [7]. Early diagnosis and treatment of the disease confer a better prognosis [3] [6]. Nevertheless, newer and better treatments are needed for aggressive malignant lymphomas [8].

Here, we analyzed the clinical signs and symptoms of 10 cases of extranodal NHL in the mandibular region presenting with mandibular symptoms, and discussed the clinical characteristics, treatment, and patient outcome.

\section{Material and Methods}

We retrospectively reviewed the medical records of 73 cases of primary malignant lymphoma that were histopathologically diagnosed at the Department of Oral and Maxillofacial Surgery, Tokyo Medical and Dental University Hospital, between April 2001 and March 2015. The observation endpoints were set at May 31, 2015. Of the 73 cases, 10 (7 men, 3 women) who presented with initial mandibular symptoms with mandibular bony involvement were included in this study. The median age of patients was 58.5 (range, 19 - 81) years at the time of first consultation in our department. The male ratio was more than double for the woman.

\section{Results}

\subsection{Previous Treatment}

The summary of the previous diagnosis and treatments were showed in Table 1. Patients were diagnosed by other dental clinics as periodontitis (cases 3, 6, 7, 9, 10), periapical periodontitis (case 8), pulpitis (cases 1, 4, 5), and decubitus ulcer (case 2) (Table 1). Root canal treatment (cases 4, 5, 8), anti-inflammatory treatment (cases 1, 3,10 ), tooth extraction (cases $6,7,9$ ), and denture adjustment (case 2) were performed before their visit to our department. The median interval from previous dental treatment to the first consultation in our department was 1 month (range, 1 week to 11 months).

The summary of the general conditions, extra- and intra-oral findings were showed in Table 2.

\subsection{General Conditions and Extra-Oral Findings}

A persistent fever above $38^{\circ} \mathrm{C}$ was observed in one case (case 5). Limb swelling and numbness and loss of sensation in the leg due to sciatic nerve palsy were observed in one case (case 5). In addition to intraoral symptoms, cervical lymphadenopathy was observed in four cases (cases 2, 3, 7, 10). Eight cases (cases 1 - 5, 8, 9, 10) had a neurological disorder to involvement of the inferior alveolar nerve.

\subsection{Intraoral Findings}

Seven cases (cases $1,3-5,8,9,10$ ) had mandibular bone swelling. Tooth mobility was observed at the first consultation in our department in four cases (cases 1, 5, 8, 9). Three cases (cases 6, 7, 9) had non-healing of the tooth extraction socket and an expanding mass in the socket at the first consultation in our department after tooth extraction was performed for severe tooth mobility at the previous dental clinic. Two cases (cases 1, 3) had tooth 
Table 1. The summary of the previous diagnosis and treatments.

\begin{tabular}{|c|c|c|c|c|}
\hline $\begin{array}{l}\text { Case } \\
\text { number }\end{array}$ & $\begin{array}{l}\text { Age at the } \\
\text { first visit }\end{array}$ & $\begin{array}{l}\text { The diagnosis by the } \\
\text { previous clinic }\end{array}$ & $\begin{array}{l}\text { The treatment by the } \\
\text { previous clinic }\end{array}$ & $\begin{array}{l}\text { Duration between previous dental } \\
\text { treatment and first consultation }\end{array}$ \\
\hline 1 & 49 & Pulpitis & Anti-inflammatory treatment & 1 week \\
\hline 2 & 80 & Decubital ulcer & Readjustment prosthesis & 2 weeks \\
\hline 3 & 19 & Periodontitis & Anti-inflammatory treatment & 1 month \\
\hline 4 & 42 & Pulpitis & Root canal treatment & 10 months \\
\hline 5 & 43 & Pulpitis & Root canal treatment & 1 month \\
\hline 6 & 68 & Periodontitis & Tooth extraction & 11 months \\
\hline 7 & 76 & Periodontitis & Tooth extraction & 7 months \\
\hline 8 & 81 & Periapical periodontitis & Root canal re-treatments & 1 month \\
\hline 9 & 70 & Periodontitis & Tooth extraction & 1 week \\
\hline \multirow[t]{2}{*}{10} & 37 & Periodontitis & Anti-inflammatory treatment & 1 week \\
\hline & Median 58.5 years & & & Median 1 month \\
\hline
\end{tabular}

Table 2. The summary of the general conditions, extra- and intra-oral findings.

\begin{tabular}{|c|c|c|c|c|c|c|}
\hline \multirow[b]{2}{*}{$\begin{array}{c}\text { Case } \\
\text { number }\end{array}$} & \multirow[b]{2}{*}{ General symptoms } & \multicolumn{2}{|c|}{ Extra-oral findings } & \multicolumn{2}{|c|}{ Intra-oral findings } & \multirow{2}{*}{$\begin{array}{c}\text { Laboratory data } \\
\text { LDH } \\
(105-210 \mathrm{IU} / \mathrm{l})\end{array}$} \\
\hline & & $\begin{array}{l}\text { Lymph node } \\
\text { adenopathy }\end{array}$ & $\begin{array}{c}\text { Neurological } \\
\text { disorders of the } \\
\text { inferior alveolar } \\
\text { nerve }\end{array}$ & $\begin{array}{c}\text { Mandibular } \\
\text { bone swelling }\end{array}$ & $\begin{array}{l}\text { Tooth } \\
\text { mobility }\end{array}$ & \\
\hline 1 & & & 0 & ० & o & 167 \\
\hline 2 & & o & 0 & & & 253 \\
\hline 3 & & ० & ० & ○ & & 122 \\
\hline 4 & & & ० & ○ & & 164 \\
\hline 5 & $\begin{array}{l}\text { - A constant basis of above } 38^{\circ} \mathrm{C} \\
\text { - Severe fatigue and anorexia } \\
\text { - Swelling of the limb and numbness } \\
\text { - Loss of sensation in the leg }\end{array}$ & & 0 & 0 & o & 494 \\
\hline 6 & & & & & $\begin{array}{l}\circ \rightarrow \text { Tooth } \\
\text { extraction }\end{array}$ & 217 \\
\hline 7 & & 0 & & & $\begin{array}{l}\circ \rightarrow \text { Tooth } \\
\text { extraction }\end{array}$ & 197 \\
\hline 8 & & & ० & ० & & 267 \\
\hline 9 & & & o & ० & $\begin{array}{l}\circ \rightarrow \text { Tooth } \\
\text { extraction }\end{array}$ & 193 \\
\hline 10 & & 0 & 0 & ० & & 261 \\
\hline $\begin{array}{l}\text { Incidence } \\
\text { rate }\end{array}$ & & $40.0 \%$ & $80.0 \%$ & $70.0 \%$ & $50.0 \%$ & $\begin{array}{l}50.0 \% \text { (cases } \\
\text { of exceed the } \\
\text { upper limits) }\end{array}$ \\
\hline
\end{tabular}


pain and three cases (cases 4, 5, 8) had root canal treatment for tooth pain.

\subsection{Laboratory Data}

Five cases (cases 2, 5, 6, 8, 10) of -examined cases had a high serum level of lactate dehydrogenase (LDH) (Table 2).

\subsection{Radiological Findings}

The summary of the radiological findings was observed in Table 3. Three cases (cases 6, 7, 9) had ill-defined bone destruction in an extraction socket on dental radiography and/or panoramic imaging. Three cases (cases 3, 5,8 ) revealed enlarged periodontal ligament space on panoramic radiography. Dental or panoramic radiography did not reveal a specific radiolucent lesion in the mandibular bone except for dental lesions that enabled a definitive diagnosis.

In our study, five (cases 1, 3, 5, 8, 10) of eight computed tomography (CT)-examined cases showed a slit-like appearance of cortex destruction, and all magnetic resonance imaging (MRI)-examined cases (cases 1 - 3, 5, 6, 8, 10) showed an extraosseous soft tissue mass on CT or MRI.

The summary of histopathological diagnosis, treatment and prognosis were observed in Table 4.

\subsection{Histopathological Diagnosis}

Three (cases 1, 4, 6) of eight cases were finally diagnosed as malignant lymphoma after re-biopsies (Table 2). One case (case 1) was first diagnosed as odontogenic fibroma and finally diagnosed as malignant lymphoma after 2 years and 5 months. Two cases (cases 4,6 ) were first diagnosed as inflammatory lymphoid tissue and re-biopsies were performed. Eight cases (cases 1, 2, 4, 6 - 10) were DLBCL. There was one case each of B-cell lymphoblastic lymphoma (case 3) and B-cell lymphoma, unclassifiable, with features intermediate between DLBCL and Burkitt lymphoma (case 5).

\subsection{Treatment}

R-CHOP (rituximab, cyclophosphamide, doxorubicin, vincristine, prednisolone) chemotherapy and autologous peripheral stem cell transplantation were performed for DLBCL. A case of stage IE DLBCL underwent R-CHOP

Table 3. The summary of the radiological findings.

\begin{tabular}{|c|c|c|c|c|}
\hline \multirow[b]{2}{*}{ Case number } & \multicolumn{2}{|c|}{ Dental radiography and/or panoramic imaging } & \multirow{2}{*}{$\begin{array}{l}\text { CT bone algorithum } \\
\text { Slit like cortex } \\
\text { destrucution }\end{array}$} & \multirow{2}{*}{$\begin{array}{c}\text { MRI } \\
\text { The extensive tumor } \\
\text { involvement of osseous } \\
\text { and soft tissue }\end{array}$} \\
\hline & $\begin{array}{l}\text { Ill-defined bone } \\
\text { destruction }\end{array}$ & $\begin{array}{c}\text { Periodontal } \\
\text { ligament }\end{array}$ & & \\
\hline 1 & & & ○ & ○ \\
\hline 2 & & & & ○ \\
\hline 3 & & ○ & ० & ○ \\
\hline 4 & No data & No data & No data & No data \\
\hline 5 & & ○ & $\circ$ & ○ \\
\hline 6 & ० & & & ० \\
\hline 7 & ○ & & & \\
\hline 8 & & ○ & ○ & ○ \\
\hline 9 & ○ & & No data & No data \\
\hline 10 & & & ० & ० \\
\hline Incidence rate & $33.3 \%(3 / 9)$ & $33.3 \%(3 / 9)$ & $62.5 \%(5 / 8)$ & $100.0 \%(8 / 8)$ \\
\hline
\end{tabular}


Table 4. The summary of histopathological diagnosis, treatment and prognosis.

\begin{tabular}{|c|c|c|c|c|c|c|c|}
\hline $\begin{array}{l}\text { Case } \\
\text { number }\end{array}$ & $\begin{array}{l}\text { Re-biopsies until } \\
\text { final diagnosis }\end{array}$ & $\begin{array}{l}\text { Histopathological } \\
\text { diagnosis }\end{array}$ & $\begin{array}{l}\text { Ann Arbor } \\
\text { classification }\end{array}$ & Chemotherapy & Corse & $\begin{array}{l}\text { Radiation } \\
\text { therapy (Gy) }\end{array}$ & $\begin{array}{l}\text { Clinical } \\
\text { outcome }\end{array}$ \\
\hline 1 & $\begin{array}{c}\text { 1st diagnosis:odontogenic } \\
\text { fibroma }\end{array}$ & $\begin{array}{l}\text { Diffuse large } \\
\text { B cell lymphoma }\end{array}$ & IEA & R-CHOP & 4 & 30 & N.E.D \\
\hline 2 & & $\begin{array}{l}\text { Diffuse large } \\
\text { B cell lymphoma }\end{array}$ & IVA & R-CHOP & 6 & - & N.E.D \\
\hline 3 & & $\begin{array}{l}\text { B lymphoblastic } \\
\text { lymphoma }\end{array}$ & IVA & $\begin{array}{c}\text { HyperCVAD + } \\
\text { Allogeneic hematopoietic } \\
\text { stem cell transplantation }\end{array}$ & 4 & $\begin{array}{l}\text { plus } 12 \text { Gy TBI } \\
\text { facilitates }\end{array}$ & D.O.D \\
\hline 4 & $\begin{array}{c}\text { 1st diagnosis:inflamatory } \\
\text { lymhpoid tissue }\end{array}$ & $\begin{array}{l}\text { Diffuse large } \\
\text { B cell lymphoma }\end{array}$ & IEA & R-CHOP & 3 & 40 & N.E.D \\
\hline 5 & & $\begin{array}{l}\text { B-cell lymphoma, } \\
\text { unclassifiable, with features } \\
\text { intermediate between diffuse } \\
\text { large B-cell lymphoma and } \\
\text { burkitt lymphoma }\end{array}$ & e & $\begin{array}{c}\text { R-CHOP + } \\
\text { Autologousperipheral } \\
\text { stem cell transplantation }\end{array}$ & 2 & - & D.O.D \\
\hline 6 & $\begin{array}{c}\text { 1st diagnosis:inflamatory } \\
\text { lymhpoid tissue }\end{array}$ & $\begin{array}{l}\text { Diffuse large } \\
\text { B cell lymphoma }\end{array}$ & IIEA & R-CHOP & 3 & - & D.O.C \\
\hline 7 & & $\begin{array}{l}\text { Diffuse large } \\
\text { B cell lymphoma }\end{array}$ & IIEA & R-CHOP & 6 & - & N.E.D \\
\hline 8 & & $\begin{array}{c}\text { Diffuse large } \\
\text { B cell lymphoma }\end{array}$ & IVA & R-CHOP & 8 & - & N.E.D \\
\hline 9 & & $\begin{array}{l}\text { Diffuse large } \\
\text { B cell lymphoma }\end{array}$ & IVA & $\begin{array}{c}\mathrm{R}-\mathrm{CHOP} \\
\text { (under treatment) }\end{array}$ & 7 & - & A.W.D \\
\hline 10 & & $\begin{array}{c}\text { Diffuse large } \\
\text { B cell lymphoma }\end{array}$ & IVA & $\begin{array}{c}\mathrm{R}-\mathrm{CHOP} \\
\text { (under treatment) }\end{array}$ & 5 & - & A.W.D \\
\hline
\end{tabular}

N.E.D = no evidence of disease; D.O.C = died from other cause; D.O.D = died of disease; A.W.D = alive with disease.

and radiotherapy. Hyper-CVAD (cyclophosphamide, vincristine, doxorubicin, dexamethasone) chemotherapy and allogeneic hematopoietic stem cell transplantation was performed in the case of B-cell lymphoblastic lymphoma (case 3), while R-CHOP and autologous peripheral stem cell transplantation was performed in the case of B-cell lymphoma, unclassifiable, with features intermediate between DLBCL and Burkitt lymphoma (case 5).

\subsection{Prognosis and Survival}

All DLBCL patients survived (cases 1, 2, 4, 7 - 10) except for one who died of pulmonary failure (case 6). One case each of B-cell lymphoblastic lymphoma (case 3) and B-cell lymphoma, unclassifiable, with features intermediate between DLBCL and Burkitt lymphoma (case 5) resulted in death. The disease-specific survival rate was $77.8 \%$ at 5 years.

\subsection{Case Presentations}

Case 1: A 49-year-old woman presented to our department with a 2-week history of a vague toothache and discomfort in the mandibular front teeth. She had been diagnosed with pulpitis and received anti-inflammatory treatment before her presentation. Extraoral examination revealed a diffuse swelling on the chin, and slight hypoesthesia of the left lower lip and skin on the chin. Cervical lymph nodes were not palpable. Intraoral examination revealed non-vital teeth from the right mandibular central incisor to the right mandibular canine. Dental and panoramic radiologic examination of the mandible showed irregular marginal radiolucency of the mandible at the tooth root apex from the right mandibular lateral incisor to the left lateral incisor (Figure 1(A)). CT demonstrated infiltrative, cortical, slit-like appearance of labial alveolar bone loss in the right mandible (Figure 1(B-1), 

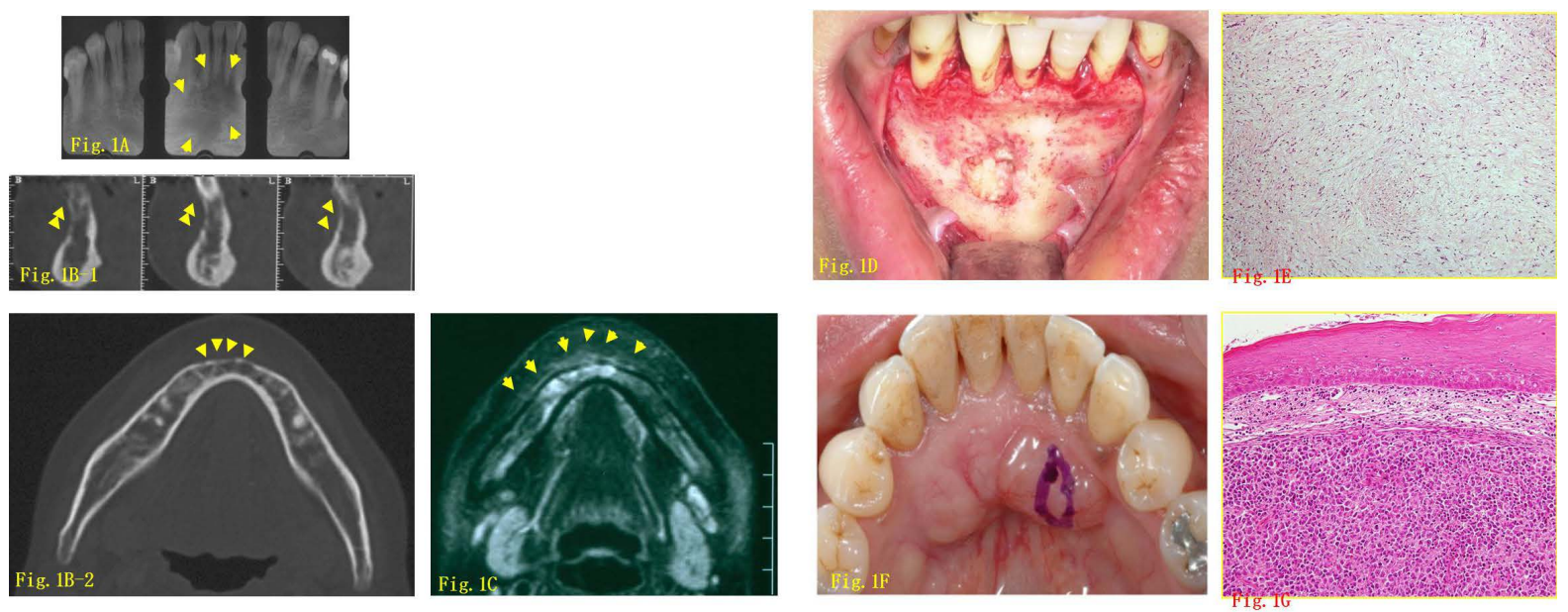

Figure 1. Case 1. 49-year-old woman with diffuse large B cell lymphoma (DLBCL), stage IE. (A) Dental radiograph of the lower teeth at the first visit. (B-1) Axial computed tomography (CT) using a bone algorithm at the first visit showing slight slit-like cortical erosion of the central labial alveolar bone of the right mandible (yellow arrows). (B-2) Transverse projection CT images. (C) Magnetic resonance imaging (MRI) of bone marrow of the mandible showed low signal intensity on T1-weighted images and intermediate to high signal intensity on T2-weighted images. (D) Intraoral photograph at the first biopsy. Subperiosteal exposure of the labial cortical bone followed by extirpation of a yellowish solid tumor and biopsy. (E) Photomicrograph of hematoxylin and eosin (H-E) staining. Thin fibrocollagenous changes of mandibular cortical bone tissue were observed. (F) Intraoral photograph (mirror image) at 2 years and 6 months after the first visit. (G) Photomicrograph of H-E staining. The connective tissue under the oral epithelium was replaced by prominent and lymphoid follicle-like nodular proliferations. The tumor was composed of atypical cells with large multilobulated nuclei.

Figure 1(B-2)). MRI showed involvement of the surrounding soft tissue outside the cortical mandibular bone (Figure 1(C)). Histopathological examination of a biopsy from the labial cortical bone showed thin fibrocollagenous changes in the mandibular cortical bone (Figure 1(D)), and a odontogenic fibroma was consequently suspected (Figure 1(E)). She received root canal treatment for teeth starting from the right mandibular central incisor to the right mandibular canine. Despite extirpation, symptoms such as discomfort and numbness of the left lower lip persisted. Two and a half years later, two tender, gradually enlarging masses covered by normal mucosa appeared on the lingual gingiva in the mid mandible (Figure 1(F)). A biopsy of the lingual gingiva was performed and a diagnosis of DLBCL was made based on the results of histopathology and immunohistochemistry (Figure $1(\mathrm{G})$ ). Whole body ${ }^{18} \mathrm{~F}$-FDG positron emission tomography (PET) and bone marrow aspirate showed that the tumor was localized to the mandible and it was classified as stage IE according to the Ann Arbor staging system. The common presenting signs and symptoms were category " $\mathrm{A}$ " because of the lack of general signs and symptoms. Two cycles of R-CHOP followed by external beam radiation therapy (30 Gy in 15 fractions) were given, and complete remission has been maintained up during 88 months.

Case 3: A 19-year-old man presented to our department with a 1-month history of numbness of the left lower lip and swelling of the left mandibular molar region. He had received anti-inflammatory treatment for the third left mandibular molar but the symptoms had worsened. On extraoral examination, a fixed, elastic hard mass occupying the region from the left masseter to submandibular region was palpable (Figure 2(A)). Paresthesia of the left skin on the chin was present. On intraoral examination, reddening and swelling of the mucosa around the third left mandibular molar was observed, and a hard mass was palpable under the lingual and buccal mucosa around the third left mandibular molar. Radiographically, a radiolucent lesion of the tooth socket of the third left mandibular molar was detected (Figure 2(B)) and CT demonstrated an infiltrative, slit-like appearance of cortical bone erosion in the left mandible (Figure 2(C)). On MRI, the bone marrow in the left mandible showed low signal intensity on T1-weighted images, high signal intensity on T2-weighted, fat suppression (FS) images, and homogeneous moderately high signal intensity on Gd-enhanced, T1-weighted images (Figure 2(D-1), Figure 2(D-2)). The lobulated tumor had spread extensively to the surrounding soft tissue from the masticator space to the submandibular spaces, and showed high signal intensity on T2-weighted (FS) images (Figure 2(D-1), Figure 2(D-2), Figure 2(D-3)). A diagnosis of B-cell lymphoblastic lymphoma was made based on results of a biopsy from the submucosal mandibular lesion at the retromandibular trigone on the left side (Figure 2(E)). 

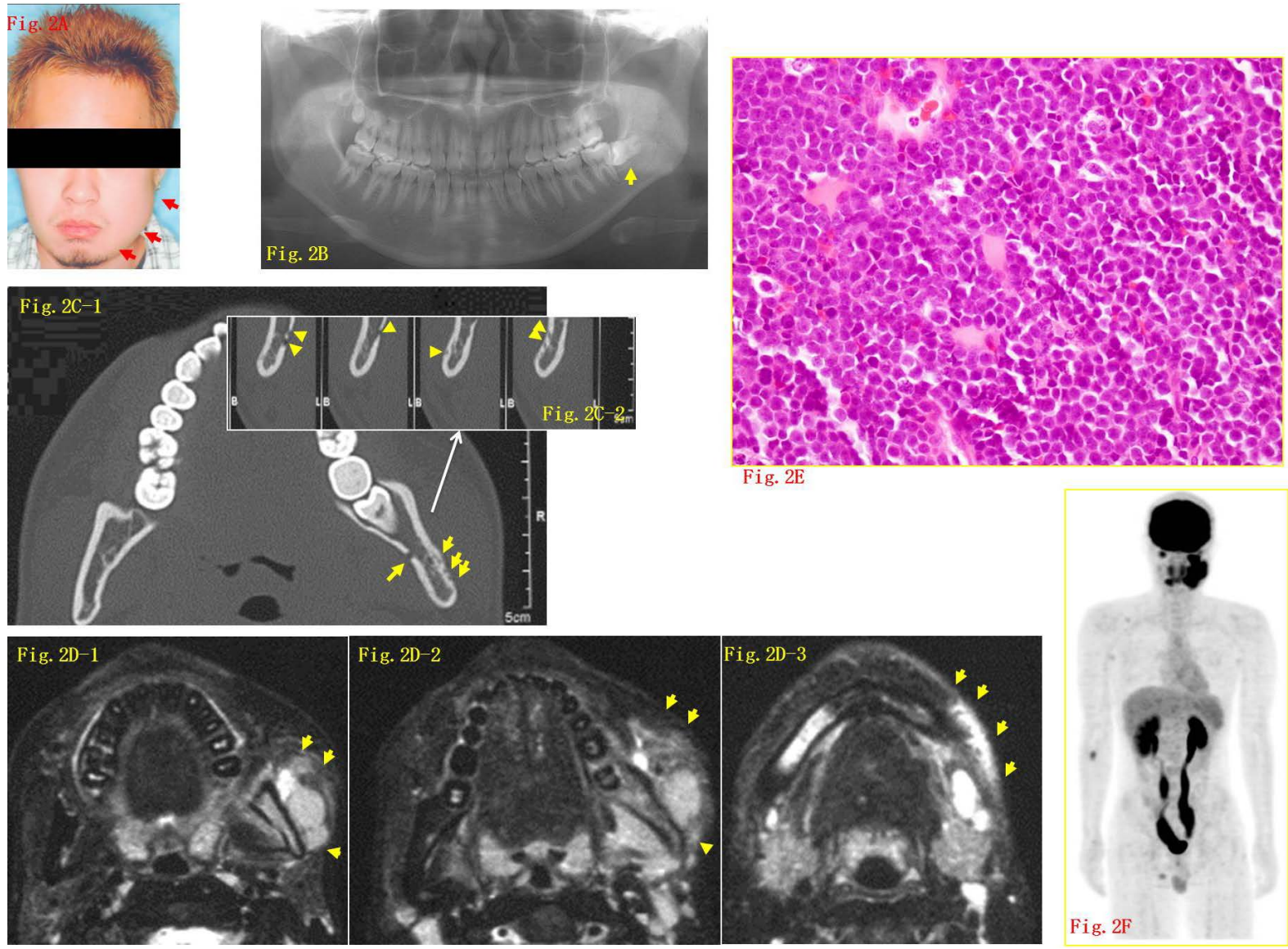

Figure 2. Case 3. 19-year-old man with B-cell lymphoblastic lymphoma, stage IV. (A) Extraoral photograph at the first visit. The left buccal region was swollen. (B) Panoramic radiograph at the first visit. (C-1) Axial CT using a bone algorithm. The infiltrative slit-like appearance of buccal and lingual sides of cortical bone erosion of the left mandible. Most of the cortex of the mandible remained intact. (C-2) Transverse projection CT images. (D-1, D-2) Gd-enhanced, T1-weighted MRI image at the first visit. Gd-enhanced, T1-weighted MRI image at the first visit. MRI showed homogeneous intermediate to moderately high signal intensity on Gd-enhanced, T1-weighted images of the bone marrow from the left premolar region to the left condyle. The lobulated tumor had spread extensively to the surrounding soft tissue, the masseter, and the submandibular spaces, and showed a homogeneous, moderately high signal intensity on the Gd-enhanced, T1-weighted images. (D-3) The lobulated tumor had extensively spread to the submandibular spaces and showed a homogeneous, moderately high signal intensity on Gd-enhanced, T1-weighted images. (E) Photomicrograph of H-E staining showed large-sized atypical lymphoid cells with a diffuse growth pattern. (F) MIP image of ${ }^{18}$ F-FDG.

Examination of whole body 18F-FDG PET/CT (Figure 2(F)) and bone marrow aspirate showed that the tumor was localized to the mandible and was therefore classified as stage IVA. The patient died despite four cycles of hyper-CVAD, allogeneic hematopoietic stem cell transplantation plus $12 \mathrm{~Gy}$ total body irradiation.

Case 5: A 43-year-old woman presented to our department with a 2-month history of numbness of the left lower lip after pulpectomy for pulpitis of the second left mandibular premolar. She had a persistent fever above $38^{\circ} \mathrm{C}$, severe fatigue, and anorexia. She also had limb swelling and numbness and loss of sensation in the leg due to sciatic nerve palsy. Hypoesthesia of the left skin on the chin was also present. Oral examination showed swelling of the buccal gingiva of the first left mandibular premolar (Figure 3(A)) and severe tooth mobility. Radiographically, it was difficult to detect a specific radiolucent lesion of the mandibular body (Figure 3(B)). CT demonstrated clear cortical bone destruction on the buccal side of the left mandible (Figure 3(C)). MRI demonstrated soft tissue masses on the buccal side outside the mandibular cortex with a heterogeneous high signal intensity on T2-weighted (FS) image (Figure 3(D)). Examination of the biopsy from the submucosal mandibular lesion at the first left mandibular premolar revealed B-cell lymphoma. It was difficult to reach the final diagnosis but the consensus was B-cell lymphoma, unclassifiable, with features intermediate between DLBCL and 

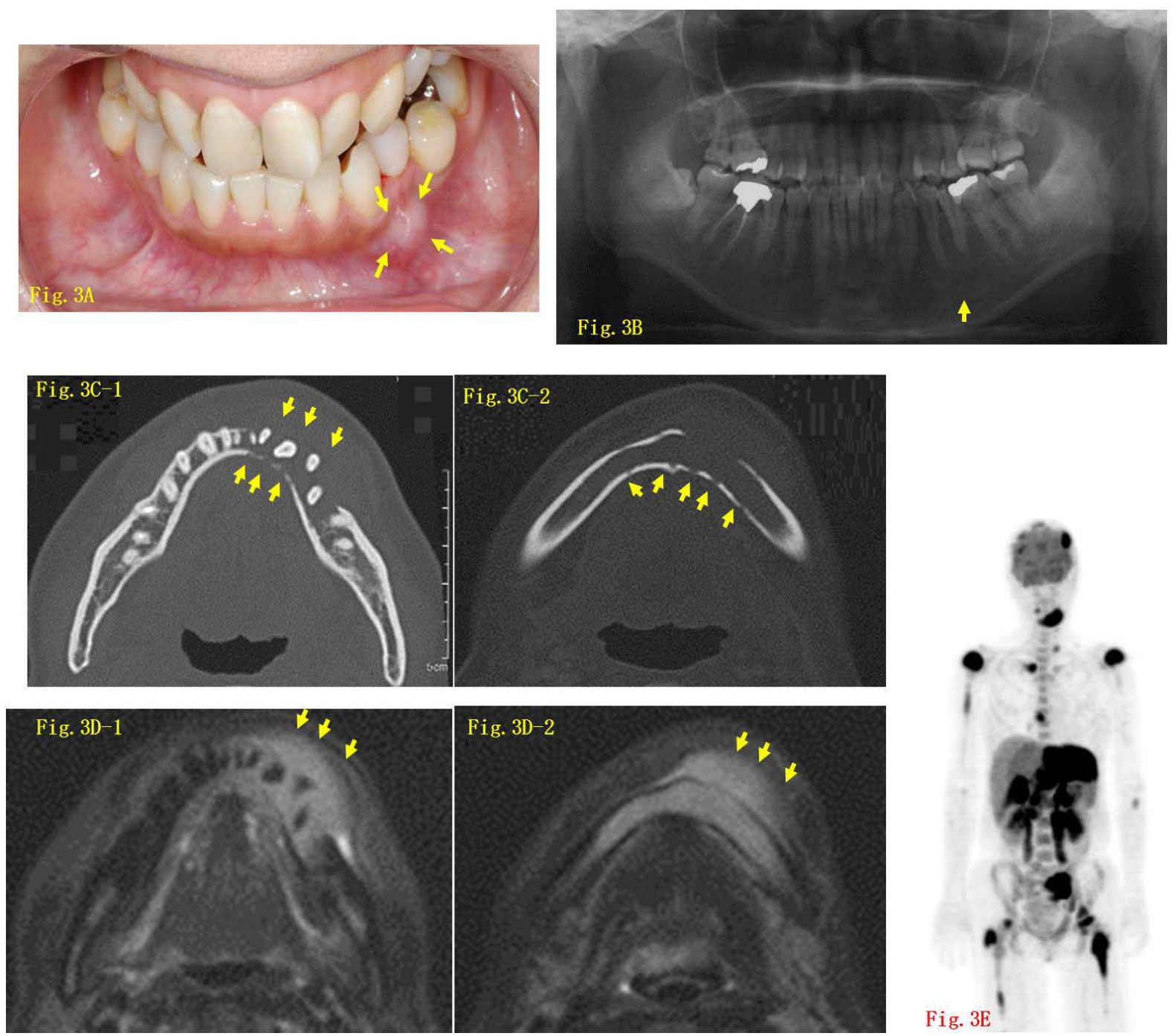

Figure 3. Case 5. 43-year-old woman with B-cell lymphoma, unclassifiable, with features intermediate between DLBCL and Burkitt lymphoma, stage IVB. (A) Intraoral photograph at the first visit. (B) Panoramic radiograph at the first visit. (C-1) Axial CT using a bone algorithm. The emphatic cortical bone destruction of the buccal side of the left mandible from the right mandibular incisior to the first left mandibular molar. (C-2) Axial CT using a bone algorithm showing a slit-like appearance of erosion on the lingual side of the cortical bone. (D-1, D-2) MRI on T2-weighted, fat suppression image at the first visit. (E) MIP image of 18F-FDG PET/CT.

Burkitt lymphoma. Based on the findings of whole body 18F-FDG PET (Figure 3(E)), the mandibular tumor was classified as stage IVB according to the Ann Arbor staging system. The patient died despite two cycles of R-CHOP and autologous peripheral stem cell transplantation.

\section{Discussion}

\subsection{Clinical Characteristics}

NHL of the mandibular region was seen between the ages of 40 and 50, [9] with a male: female ratio of 2:1 [9] [10]. We encountered one case of B-cell lymphoblastic lymphoma in a 19-year-old. Lin et al. reported that $68.0 \%$ (17/25) of B-cell lymphoblastic lymphoma patients were male, with a median age of 20 years at the time of presentation [11]. Therefore, it was considered that B-cell lymphoblastic lymphoma occurs around 20 years of age in men. The peak age and clinical features of B-cell lymphoma, unclassifiable, with features intermediate between DLBCL and Burkitt lymphoma are not well described. 


\subsection{Symptoms}

Malignant lymphoma occasionally infiltrates nerves, causing axonal damage [12] and peripheral nerve complications. The clinical presentation of mandibular NHL is usually a neurological disorder secondary to involvement of the inferior alveolar nerve [4] [13] and paresthesia of $20 \%-100 \%$ of the skin supplied by the inferior alveolar nerve is common [14]. In our case series, $80.0 \%$ of cases had a neurological disorder secondary to involvement of the inferior alveolar nerve. The patient who had limb swelling and sciatic nerve palsy (case 5) was stage IV and had a poor prognosis. Considerable attention should be given to investigate the underlying cause if a neurological symptom is observed.

Gusenbauer et al. emphasized that malignant lymphoma of the mandible should be included in the differential diagnosis other than odontogenic infection, periodontitis, or localized osteomyelitis if clinically unexplained dental pain, facial swelling, mucosal mass, gingival swelling, persistent ulceration of mouth mucosa, [4] [15] [16] unexplained tooth mobility or non-healing mass of the extracted tooth socket [4] [16] is present.

Malignant lymphoma of the mandibular region is occasionally diagnosed as dental lesions, resulting in unfocused dental treatment and tooth extractions [15]. Dentists discovered that the lesions were not caused by dental disease only after failure of routine dental treatments in resolving unexplained symptoms as well as routine clinical and radiological assessments. For this reason, consultation in a specialized department was often delayed by three months in cases of mandibular NHL [9] [17]. In our study, there was a median interval of 1 month between dental treatment and the first specialist consultation. It was noted that three of five cases with tooth mobility underwent extraction in dental clinics. If unexplained tooth mobility is present, the dentist should not extract the tooth without considering the possibility of malignant lymphoma, as recommended in previous reports [4] [16].

\subsection{Radiological Findings}

Panoramic Imaging Findings

Panoramic films occasionally show widening of the mandibular canal, mental foramen, or periodontal ligament, and loss of the lamina dura and ill-defined bone destruction [16]-[19]. However, many cases do not show a specific radiolucent lesion in the mandible on plain film, except for dental lesions, so a definitive diagnosis might be difficult based on dental or panoramic radiography [20]. If unexplained, non-specific clinical features except for dental lesions on routine dental and panoramic radiologic examination are observed, oral surgeons and dentists should request CT, MRI [4] [16]. Staging should be performed to determine overall orientation and spread of the tumor into nodal and visceral areas by standard modalities such as whole-body PET/CT [4] [16] [17].

NHL of the mandible region manifests as bone destruction with a slit-like appearance with no widening and clear destruction of the cortex [14]. It is difficult to detect the slight erosion of the cortex during surgical examination [21] [22].

Hicks et al. evaluated the histopathologic findings of primary extranodal NHL affecting the bone and reported that osteoclasts form tunnels penetrating the cortex and that the tumor spreads from the marrow to the surrounding soft tissue through these cortical tunnels [23]. In addition, Yasumoto et al. noted that the gingival mass of extranodal NHL frequently erode into marrow spaces without entirely destroying the cortex [22]. Such characteristic tumor-spreading patterns are reflected by CT and MRI findings [20]. MRI was superior to CT in evaluating extensive tumor involvement of osseous and soft tissues. On MRI, the tumor tends to show homogeneous low signal intensity (isointense to muscle) on T1-weighted images and high intensity on T2-weighted images. It is homogeneously enhanced after contrast administration [24] and may show additional characteristic findings on dynamic contrast-enhanced MRI. A low apparent diffusion coefficient (ADC) of NHL of the cervical lymph nodes was useful in differentiating NHL from squamous cell carcinoma [20] [25] [26]. PET/CT should be performed to determine overall orientation and spread of the tumor on the whole body [17].

\subsection{Pathological Diagnosis}

Our study suggests that the pathological diagnosis should be based on a deep bone biopsy, as reported previously [9]. In addition, biopsy samples should be large enough to facilitate examinations such as immunohistopathological analyses and flow cytometry [16] [27], as well as cryopreservation in certain cases.

DLBCL is more common in the mandibular region [28]. To our knowledge, there are few case reports of B-cell lymphoblastic lymphoma with a mass in the mandible [29] [30]. We experienced one case of B-cell lym- 
phoma, unclassifiable, with features intermediate between DLBCL and Burkitt lymphoma (case 5). This type of lymphoma was newly categorized in the 4th edition of WHO Classification of Tumours of Hematopoietic and Lymphoid Tissues [31] and is a poorly characterized entity [8]. Its occurrence in the oral cavity has been reported recently [7] [32], to our knowledge, our case is the first report of the entity arising in the mandibular region.

\section{Treatment and Prognosis}

Ruijs et al. suggested that 35 - 40 Gy of radiotherapy is adequate for treating localized (stage I and II) lymphoma. [33] It has been reported that intermediate- and high-grade lymphoma respond well to combined chemotherapy and radiotherapy [34] [35]. A combination regimen with rituximab has been reported to be efficacious for DLBCL and follicular lymphoma but some tumors are refractory to rituximab. The reasons for such resistance and the mechanisms of targeting CD20 and other B cell antigens are unclear [36]. There is no established therapy for B-cell lymphoblastic lymphoma or B-cell lymphoma, unclassifiable, with features intermediate between DLBCL and Burkitt lymphoma. Further studies on effective treatment for these two types of malignant lymphomas are needed.

The prognosis of NHL depends mainly on histological type, tumor stage, number of extranodal sites of involvement, and age [37]. Stage I NHL has a 5-year survival rate of 70\% [38] to 83\% [39], stage II NHL has a 5-year survival rate of $49 \%$ [39], and survival declines to $20 \%$ or below for stages II-IV [38]. In our study, all stage IE and II patients have survived except for one who died of pulmonary failure, whereas 2 of 6 cases with stage IVA or IVB disease had died. Stage IV lymphoma had a poor prognosis except for DLBCL. Despite difficulties in interpreting the clinical picture and the consequently delayed treatment of NHL of the mandible bone, prognosis of DLBCL is good [28]. In our study, 4 cases of DLBCL with Stage IV have survived. The prognosis of NHL does not depend on the tumor site [28]. The survival rate in our study was similar to those in previous reports [37]-[39].

\section{Conclusion}

Malignant lymphoma must be considered in the differential diagnosis if unexplained symptoms such as swelling of the jaw, pain, neurological disorder due to suspected involvement of the inferior alveolar nerve, tooth mobility, or cervical lymphadenopathy is present. The dentist should not extract a loose tooth with an unidentifiable cause. If unexplained non-specific clinical symptoms are observed, oral surgeons and dentists should request CT, MRI or PET/CT. NHL of the mandible region has a slit-like appearance with no widening and clear destruction of the cortex bone on CT, and extensive tumor involvement of osseous and soft tissues are clearer on MRI. A deep bone biopsy is preferred for suspected malignant lymphoma.

\section{Acknowledgements}

The authors would like to thank the nurses and other medical staff who assisted in this study.

\section{References}

[1] Kuppers, R. (2015) Mechanisms of B-Cell Lymphoma Pathogenesis. Nature Reviews Cancer, 5, 251-262. http://dx.doi.org/10.1038/nrc1589

[2] Kobler, C. and Effenberger, F. (2005) Stereoselective Synthesis of Cis-p-menth-8-ene-1,7-diol, Cis-p-menthane-1,7diol, and Cis-p-menthane-1,7,8-triol. Chemistry, 11, 2783-2787. http://dx.doi.org/10.1002/chem.200401147

[3] Guevaracanales, J.O., Morales-Vadillo, R., de Faria, P.E., Sacsaquispe-Contreras, S.J., Leite, F.P. and Chaves, M.G. (2011) Systematic Review of Lymphoma in Oral Cavity and Maxillofacial Region. Acta Odontológica Latinoamericana, 24, 245-250.

[4] Bachaud, J.M., Coppin, D., Douchez, J., Boutault, F., Paty, E., Saboye, J. and Barthelemy, I. (1992) Primary Malignant Lymphoma of the Mandible. A Study of 3 Cases and a Review of the Literature. Revue de Stomatologie et de Chirurgie Maxillo-Faciale, 93, 372-376.

[5] Huvos, A.G. (1991) Primary Non-Hodgkin's Lymphoma of Bone. 2nd Edition, Bone Tumours: Diagnosis, Treatment, and Prognosis, Saunders, Philadelphia, 625-637.

[6] Epstein, J.B., Epstein, J.D., Le, N.D. and Gorsky, M. (2001) Characteristics of Oral and Paraoral Malignant Lymphoma a Population Based Review of 361 Cases. Oral Surgery, Oral Medicine, Oral Pathology, Oral Radiology, and En- 
dodontology, 95, 519-525. http://dx.doi.org/10.1067/moe.2001.116062

[7] Jaradat, J.M., Potluri, A. and Bilodeau, E.A. (2013) B-Cell Lymphoma, Unclassifiable, with Features Intermediate between Diffuse Large B-Cell Lymphoma and Burkitt Lymphoma: Report of a Case in the Oral Cavity. Indian Journal of Dental Research, 24, 384-386. http://dx.doi.org/10.4103/0970-9290.118016

[8] Perry, A.M., Crockett, D., Dave, B.J., Althof, P., Winkler, L., Smith, L.M., Aoun, P., Chan, W.C., Fu, K., Greiner, T.C., Bierman, P., Gregory Bociek, R., Vose, J.M., Armitage, J.O. and Weisenburger, D.D. (2013) B-Cell Lymphoma, Unclassifiable, with Features Intermediate between Diffuse Large B-Cell Lymphoma and Burkitt Lymphoma: Study of 39 Cases. British Journal of Haematology, 162, 40-49. http://dx.doi.org/10.1111/bjh.12343

[9] Mnejja, M., Hammami, B., Kolsi, N., Kallel, S., Chakroun, A., Charfeddine, I., Hdiji, S., Elloumi, M. and Ghorbel, A. (2010) B-Cell Lymphoma of the Mandible. European Annals of Otorhinolaryngology, Head and Neck Diseases, 127, 186-188. http://dx.doi.org/10.1016/j.anorl.2010.07.009

[10] Kini, R., Saha, A. and Naik, V. (2009) Diffuse Large B-Cell Lymphoma of Mandible: A Case Report. Medicina Oral Patología Oral y Cirugia Bucal, 14, e421-e424.

[11] Lin, P., Jones, D., Dorfman, D.M. and Medeiros, L.J. (2000) Precursor B-Cell Lymphoblastic Lymphoma: A Predominantly Extranodal Tumor with Low Propensity for Leukemic Involvement. The American Journal of Surgical Pathology, 24, 1480-1490. http://dx.doi.org/10.1097/00000478-200011000-00003

[12] Kelly, J.J. and Karcher, D.S. (2005) Lymphoma and Peripheral Neuropathy: A Clinical Review. Muscle Nerve, 31, 301-313. http://dx.doi.org/10.1002/mus.20163

[13] Barber, H.D., Stewart, J.C. and Baxter, W.D. (1992) Non-Hodgkin’s Lymphoma Involving the Inferior Alveolar Canal and Mental Foramen: Report of a Case. Journal of Oral and Maxillofacial Surgery, 50, 1334-1336. http://dx.doi.org/10.1016/0278-2391(92)90240-Z

[14] Ito, J., Batth, T.S., Petzold, C.J., Redding-Johanson, A.M., Mukhopadhyay, A., Verboom, R., Meyer, E.H., Millar, A.H. and Heazlewood, J.L. (2011) Analysis of the Arabidopsis Cytosolic Proteome Highlights Subcellular Partitioning of Central Plant Metabolism. Journal of Proteome Research, 10, 1571-1582. http://dx.doi.org/10.1021/pr1009433

[15] Gusenbauer, A.W., Katsikeris, N.F. and Brown, A. (1990) Primary Lymphoma of the Mandible: Report of a Case. Journal of Oral and Maxillofacial Surgery, 48, 409-415. http://dx.doi.org/10.1016/0278-2391(90)90442-5

[16] Pazoki, A., Jansisyanont, P. and Ord, R.A. (2003) Primary Non-Hodgkin's Lymphoma of the Jaws: Report of 4 Cases and Review of the Literature. Journal of Oral and Maxillofacial Surgery, 61, 112-117. http://dx.doi.org/10.1053/joms.2003.50018

[17] Parrington, S.J. and Punnia-Moorthy, A. (1999) Primary Non-Hodgkin’s Lymphoma of the Mandible Presenting Following Tooth Extraction. British Dental Journal, 187, 468-470. http://dx.doi.org/10.1038/sj.bdj.4800308

[18] Eisenbud, L., Sciubba, J., Mir, R. and Sachs, S.A. (1984) Oral Presentations in Non-Hodgkin’s Lymphoma: A Review of Thirty-One Cases. Part II. Fourteen Cases Arising in Bone. Oral Surgery, Oral Medicine, Oral Pathology, 57, 272 280. http://dx.doi.org/10.1016/0030-4220(84)90183-X

[19] Kawasaki, G., Nakai, M., Mizuno, A., Nakamura, T. and Okabe, H. (1997) Malignant Lymphoma of the Mandible: Report of a Case. Oral Surgery, Oral Medicine, Oral Pathology, Oral Radiology, and Endodontology, 83, 345-349. http://dx.doi.org/10.1016/S1079-2104(97)90241-9

[20] Imaizumi, A., Kuribayashi, A., Watanabe, H., Ohbayashi, N., Nakamura, S., Sumi, Y., Sano, T. and Kurabayashi, T. (2012) Non-Hodgkin Lymphoma Involving the Mandible: Imaging Findings. Oral Surgery, Oral Medicine, Oral Pathology and Oral Radiology, 113, e33-e39. http://dx.doi.org/10.1016/j.0000.2011.10.004

[21] Mealey, B.L, Tunder, G.S. and Pemble, C.W. (2002) Primary Extranodal Malignant Lymphoma Affecting the Periodontium. Journal of Periodontology, 73, 937-941. http://dx.doi.org/10.1902/jop.2002.73.8.937

[22] Yasumoto, M., Shibuya, H., Fukuda, H., Takeda, M., Mukai, T. and Korenaga, T. (1998) Malignant Lymphoma of the Gingiva: MR Evaluation. American Journal of Neuroradiology, 19, 723-727.

[23] Hicks, D.G., Gokan, T., O’Keefe, R.J., Totterman, S.M., Fultz, P.J., Judkins, A.R., Meyers, S.P., Rubens, D.J., Sickel, J.Z. and Rosier, R.N. (1995) Primary Lymphoma of Bone. Correlation of Magnetic Resonance Imaging Features with Cytokine Production by Tumor Cells. Cancer, 75, 973-980. http://dx.doi.org/10.1002/1097-0142(19950215)75:4<973::AID-CNCR2820750412>3.0.CO;2-8

[24] Mulligan, M.E., McRae, G.A. and Murphey, M.D. (1999) Imaging Features of Primary Lymphoma of Bone. American Journal of Roentgenology, 173, 1691-1697. http://dx.doi.org/10.2214/ajr.173.6.10584821

[25] Holzapfel, K., Duetsch, S., Fauser, C., Eiber, M., Rummeny, E.J. and Gaa, J. (2009) Value of Diffusion-Weighted MR Imaging in the Differentiation between Benign and Malignant Cervical Lymph Nodes. European Journal of Radiology, 72, 381-387. http://dx.doi.org/10.1016/j.ejrad.2008.09.034

[26] King, A.D., Ahuja, A.T., Yeung, D.K., Fong, D.K., Lee, Y.Y., Lei, K.I. and Tse, G.M. (2007) Malignant Cervical 
Lymphadenopathy: Diagnostic Accuracy of Diffusion-Weighted MR Imaging. Radiology, 245, 806-813. http://dx.doi.org/10.1148/radiol.2451061804

[27] Longo, F., De Maria, G., Esposito, P. and Califano, L. (2004) Primary Non-Hodgkin’s Lymphoma of the Mandible. Report of a Case. International Journal of Oral and Maxillofacial Surgery, 33, 801-803.

http://dx.doi.org/10.1016/j.ijom.2003.12.003

[28] Djavanmardi, L., Oprean, N., Alantar, A., Bousetta, K. and Princ, G. (2008) Malignant Non-Hodgkin’s Lymphoma (NHL) of the Jaws: A Review of 16 Cases. Journal of Cranio-Maxillofacial Surgery, 36, 410-414. http://dx.doi.org/10.1016/j.jcms.2008.03.004

[29] Kim, H.J., Lee, T.J. and Choi, Y.S. (2014) Primary B-Lymphoblastic Lymphoma of Gallbladder Involving Mandibular Bone. International Journal of Hematology, 99, 790-793. http://dx.doi.org/10.1007/s12185-014-1582-2

[30] Cox, D.P., Treseler, P., Dong, R. and Jordan, R.C. (2007) Rare Oral Cavity Presentation of a B-Cell Lymphoblastic Lymphoma. A Case Report and Review of the Literature. Oral Surgery, Oral Medicine, Oral Pathology, Oral Radiology, and Endodontology, 103, 814-819. http://dx.doi.org/10.1016/j.tripleo.2005.11.037

[31] de Jong, D. (2009) Novel Lymphoid Neoplasms-The Borderland between Diffuse Large B-Cell Lymphoma and Burkitt's Lymphoma. Haematologica, 94, 894-896. http://dx.doi.org/10.3324/haematol.2009.008128

[32] Owosho, A.A., Bilodeau, E.A., Surti, U. and Craig, F.E. (2014) Large B-Cell Lymphoma of the Base of the Tongue and Oral Cavity: A Practical Approach to Identifying Prognostically Important Subtypes. Oral Surgery, Oral Medicine, Oral Pathology and Oral Radiology, 118, 338-347. http://dx.doi.org/10.1016/j.0000.2014.06.002

[33] Ruijs, C.D., Dekker, A.W., van Kempen-Harteveld, M.L., van Baarlen, J. and Hordijk, G.J. (1994) Treatment of Localized Non-Hodgkin's Lymphomas of the Head and Neck. Cancer, 74, 703-707. http://dx.doi.org/10.1002/1097-0142(19940715)74:2<703::AID-CNCR2820740225>3.0.CO;2-P

[34] Donato, V., Iacari, V., Zurlo, A., Nappa, M., Martelli, M., Banelli, E., Enrici, R.M. and Biagini, C. (1998) Radiation Therapy and Chemotherapy in the Treatment of Head and Neck Extranodal Non-Hodgkin's Lymphoma in Early Stage with a High Grade of Malignancy. Anticancer Research, 18, 547-554.

[35] Beal, K., Allen, L. and Yahalom, J. (2006) Primary Bone Lymphoma: Treatment Results and Prognostic Factors with Long-Term Follow-Up of 82 Patients. Cancer, 106, 2652-2656. http://dx.doi.org/10.1002/cncr.21930

[36] Pie-Sanchez, J., Petit, J., Figueiredo, R. and Gay-Escoda, C. (2011) Primary Diffuse Large B-Cell Lymphoma of the Mandible: A Case Report. Minerva Stomatologica, 60, 87-92.

[37] Mawardi, H., Cutler, C. and Treister, N. (2009) Medical Management Update: Non-Hodgkin Lymphoma. Oral Surgery, Oral Medicine, Oral Pathology, Oral Radiology, and Endodontology, 107, e19-e33. http://dx.doi.org/10.1016/j.tripleo.2008.08.054

[38] Slootweg, P.J., Wittkampf, A.R., Kluin, P.M., de Wilde, P.C. and van Unnik, J.A. (1985) Extranodal Non-Hodgkin's Lymphoma of the Oral Tissues: An Analysis of 20 Cases. Journal of Maxillofacial Surgery, 13, 85-92. http://dx.doi.org/10.1016/S0301-0503(85)80022-9

[39] Economopoulos, T., Asprou, N., Stathakis, N., Fountzilas, G., Pavlidis, N., Papaspyrou, S., Dervenoulas, J., Belia, M., Papageorgiou, E., Theoharis, D., et al. (1992) Primary Extranodal Non-Hodgkin's Lymphoma of the Head and Neck. Oncology, 49, 484-488. 